\title{
Primitivos modernos:
} Arte Picasso, Manuel Mujica Gallo y el I.A.C

Ramón Mujica Pinilla

A mi madre, Marisa

De la Edad de Piedra a nuestros días que tal retroceso! Johm Lodge

Uno de los rubros del arte moderno más fascinantes para el historiador de las ideas estéticas es el uso contemporáneo de símbolos y formas pertenecientes a las así llamadas culturas primitivas. Este fenómeno se inició en los albores del siglo XX y fue la consecuencia tardía e indirecta de las nuevas corrientes teóricas en la etnografía europea. A lo largo de la segunda mitad del XIX, diversos etnógrafos Etward Tylor, Sir John Lubbock, William Oldsfield, Gottfried Semper -entre otros- elaboraron un replanteamiento total sobre los orígenes, evolución, función y significado del arte en los pueblos tradicionales ajenos o alejados de la civilización occidental. Ya para 1885 los museos etnográficos europeos contaban con un registro completo de todos los tipos y manifestaciones de arte primitivo en el mundo -objetos que estilísticamente pasaban del naturalismo a la abstracción formal más extrema- y que servirían posteriormente de modelo o inspiración visual para la plástica moderna de Gauguin, Matisse, Kandinsky, Klee y Picasso, entre otros'. El arte moderno, en otras palabras, se inicia como un rompimiento formal con los cánones estrictos del clasicismo académico asociado con el dibujo realista de perfección anatómica y desarrolla sus nuevas teorías de la forma y del color tras entrar en contacto con el arte primitivo. Este interés, hay que reconocerlo, era esencialmente estilístico y no iconográfico. Los artistas modernos intuían más no les interesaba el sentido original ni el significado real de las piezas que imitaban. Retomaban los motivos antiguos como formas artísticas y se dejaban llevar subjetivamente por su compleja y extraordinaria vitalidad resaltando la expresividad emocional de su colorido y composiciones. La modernidad, en otras palabras, preconizaba el fondo humano del arte arcaico incentivando estilos artísticos deliberadamente primitivos y libres en la combinación de formas y colores.

\footnotetext{
Robert Goldwater. Primitivism in Modern Art. The Belknap Press of Harvard University Press, 1966, p. 16 Para una comparación entre la estética "primitiva" y la contemporánea véase, Antoni Tapies, El arte y sus lugares. Ediciones Siruela, Madrid, 1999. Cabe recordar que en 1854 cuando la familia de Paúl Gaugin se trasladó por unos años al Perú, Aline Tristan madre del célebre pintor e hija de la escritora socialista Flora Tristán (1803-1844) hizo una buena colección de cerámica peruana prehispánica que heredó e influyo sobre la pintura y escultura de su hijo como se constata en el "ídolo" pintado que figura dentro de su retrato a Marie-Angélique Satre titulado La Belle Angéle (1889).
} 


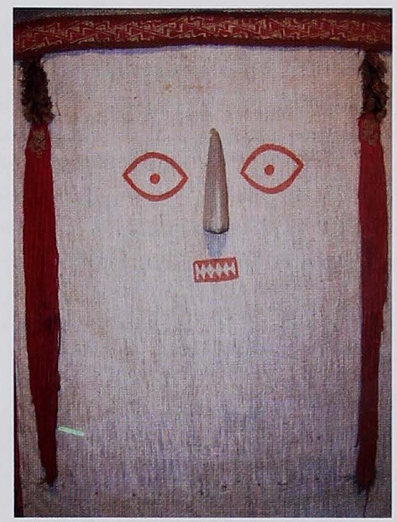

(fig. 1) Tela pintada Chancay.

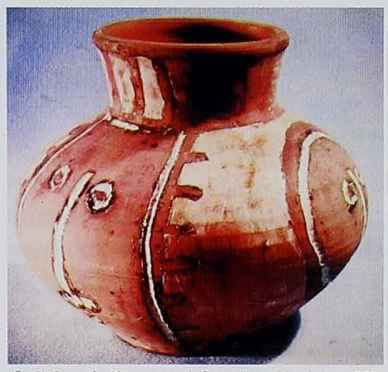

(fig.2) Ceramio Picasso con influencia prehispánica. 1953.

Picasso (1881-1973) fue, sin duda, uno de los primeros artistas modernos en utilizar para sus creaciones fuentes visuales provenientes de civilizaciones antiguas o de la cultura preindustrial. Su interés por el arte primitivo se inicia después de su periodo azul (1901-1904) y rosa (1904-1906), cuando elabora -entre 1906 y 1907- toda una serie de experimentos formales que articulan el primer lenguaje pictórico realmente moderno. Es en este periodo que estudia la escultura ibérica arcaica de la cual el Museo del Louvre poseía una buena colección de piezas provenientes de una excavación en Osuna descubierta en 1905. En 1907 Picasso visita el Museo del Trocadero en París y queda profundamente impactado con la escultura africana. Ya para estas fechas incluso coleccionaba los "ídolos" y máscaras africanas y de Oceanía que decoraban su atelier de Bateau Lavoir en Montmartre, París. De hecho dos de los rostros-máscara de las Señoritas de Avignon una de sus obras maestras precedida por 807 estudios para su realización- ya delatan las deformaciones estilísticas africanas ${ }^{3}$. En su periodo cubista (1907-1915) también sobrevive el estatismo del arte primitivo que anula la noción moderna de la perspectiva y del espacio físico en su intento por concebir y mirar a un objeto tridimensional desde perspectivas distintas. Al hacerlo, sus formas se vuelven geométricas y se purifican de sus rasgos individuales convirtiéndose en una realidad abstracta. Pero la creatividad embriagadora, inagotable y vanguardista de Picasso lo trastocaba todo con nuevos medios expresivos. Con audacia contestataria y actitud desafiante primitiviza a los grandes pintores flamencos y del barroco español. Su Guernica, pintado en 1937, cuyo nombre proviene de la ciudad vasca bombardeada por las fuerzas aéreas falangistas, se basó en una composición alegórica de Pedro Pablo Rubens: Los horrores de la guerra. Los personajes mitológicos utilizados por Rubens se convierten en manos del artista malagueño en los símbolos de la nueva guerra moderna y de su exterminio de masas en poblaciones civiles ${ }^{4}$. Picasso también

Ibid, p. 145

Véase Cap. 6 de Carsten-Peter Warncke.Pablo Picasso 1881-1973. Taschen 1997, Alemania.

Santiago Sebastián "El Guernica de Picasso: Simbolismo e interpretación" en Arte y Arqueología. 8-9. Instituto de Estudios Bolivianos, Museo Nacional de Arte, La Paz, 1982-1983, 85-112. Aguilera Cerni, por su lado, ha encontrado en el Guernica elementos iconográficos provenientes del Apocalipsis del Beato de Liébana (s.VIII), de los grabados de Durero sobre el mismo tema, del Juicio Final de Miguel Ángel y de los Desastres de la Guerra (1812-1820) de Goya (véase, Luis Carlos Rodrigo Mazuré. Picasso en sus carteles. Imagen y Obra. Tomo III. Arte Ediciones, Madrid, 1992, p. 1586 
copia y desfigura las composiciones clásicas de Lucas Cranach, Rafael y El Greco. Elabora su propia versión de las Meninas (1957) de Velásquez y reconstruye los bodegones o naturalezas muertas barrocas.

Gracias al testimonio personal de mi padre, Manuel Mujica Gallo (1906-1972), amigo del pintor, existe evidencia concluyente de que durante los años 50 y 60 , Picasso fue expuesto a otra fuente visual arcaizante que le sirvió de inspiración para su obra pictórica y escultórica: el arte prehispánico del Perú (figs.1, 2). Una rápida visión sintética de la coyuntura cultural de la Lima de aquel entonces ayudará a comprender lo que motivó al escritor peruano a conocer e intimar con el maestro español.

En el mes de julio de 1955, la revista Cultura Peruana (No. 85) anuncia la inauguración en Lima del Instituto de Arte Contemporáneo (I.A.C) publicando una caricatura de su flamante presidente, Manuel Mujica Gallo, dibujada por Málaga Grenet ${ }^{5}$. Difundía la noticia de que diversos artistas locales -Lajos D'Ebneth, Ricardo Grau, Sigfredo Laske, Juan Luis Pereira, Fernando de Szyszlo, Macedonio de la Torre y Juan Manuel Ugarte Eléspuru- a modo de apoyo financiero a dicha institución habían donado 26 obras de arte para su venta. El I.A.C, como lo asevera el primer número de su revista y folletería temprana, buscaba llenar un vacío para la plástica peruana y se convierte en la institución que impulsó y tuvo mayor influencia en el desarrollo del arte moderno en el Perú. Existían ya varias galerías de arte en Lima. Estaba la galería de arte del holandés Bob Gésinus que funcionaba en la Quinta Heeren y que vendía verdaderas obras maestras de arte clásico europeo: lienzos de Rembrandt, Tintoretto, Rubens, Van Dyck, Boucher, entre otros. La Galería Gesinus también organizó la primera exposición de pintura impresionista en el Perú y vendió una Catedral de Rouen de Monet ${ }^{6}$. También existían la Galería San Marcos, el Museo de Reproducciones Pictóricas de la UNMSM y La Galería de Lima, abierta esta última en 1947 en la calle Mogollón por Francisco Moncloa y Jorge Remy. Aquí por vez primera en Lima se expuso la tendencia pictórica del arte abstracto o no figurativo inaugurada por Fernando de Szyszlo, Enrique Kleiser, Rodríguez Larraín y Jorge Piqueras y seguidos más tarde por Alberto Dávila y Carlos Aitor Castillo entre otros? .

Al clausurarse la Galería de Lima tras casi diez años de existencia, un grupo de académicos y aficionados decidieron fundar el I.A.C. ${ }^{8}$ La heterogeneidad ideológica de su primera junta directiva delataba su mirada interdisciplinaria. La encabezaba el ya mencionado Mujica Gallo, de vicepresidente estaba el arquitecto Fernando Belaúnde Terry (quien sería presidente del Perú entre 1963 y 1968), de tesorero

La referencia me ha sido gentilmente proporcionada por Luis Fernando Villegas Torres.

Fernando de Szyszlo. Miradas Furtivas. Antología de textos (1955-1966). Fondo de Cultura Económica. Lima, 1996.

Mirko Lauer. La Introducción a la pintura peruana del siglo XX. Mosca Azul Editores, Lima, 1976, p. 152.

En el primer número de la Revista del Instituto de Arte Contemporáneo publicada en julio de 1955 se dice: intelectuales, artistas y hombres de las más diversas profesiones, crearon, a raiz del cierre de la Galería de Lima, el instrumento de renovación de nuestro ambiente cultural: el Instituto de Arte Contemporáneo. El último local del I.A.C sería el Museo de Arte Italiano y cerraría en 1972, durante el gobierno militar, según consta en la liquidación de dicha institución del 20 de septiembre realizada por su último director Alfonso Castrillón Vizcarra. 
Walter Gross, de secretario Augusto Álvarez Calderón, Francisco Moncloa de Director del Ejecutivo y como directivos Elvira Luza, Carlos A. Seguín, Luis Miro Quesada G, Manuel Checa S, José María Arguedas y Sebastián Salazar Bondy quien invitaría a Luís Carlos Rodrigo Mazuré a la directiva ${ }^{9}$. En un inicio, los intereses de fondo del I.A.C no eran muy distintos a los del Instituto de Arte Peruano fundado en 1931 en el Museo Nacional de Cultura Peruana por el pintor costumbrista y escritor José Sabogal (18881957). A decir, estudiar y dar a conocer el arte peruano de todos los tiempos: prehispánico, virreinal y republicano con sus derivaciones mestizas en las artes populares. De hecho, a menos de tres meses de iniciadas sus actividades, en homenaje al pintor Mario Urteaga (1875-1957) el I.A.C realiza una exposición retrospectiva de su obra pero convocando a tres conferencistas que tenían abiertos discursos discrepantes que, inevitablemente, generaron un tenso ambiente de polémica $^{10}$. A decir verdad, las diferencias entre el I.A.P. y el I.A.C. eran más teóricas que temáticas. Mientras el indigenismo de Sabogal -a quien José Carlos Mariátegui describió como el primer pintor peruano "- buscaba definir los rasgos propios de un arte nacional, el I.A.C se propone divulgar, con exposiciones didácticas, la historia del arte peruano, incluyendo a sus jóvenes valores, pero para analizarlos con categorías estéticas cosmopolitas y contemporáneas. Ya lo puntualizaba Luis Miró Quesada en un artículo de El Comercio:

De todas las ideologías con que quiere revestirse el arte ninguna tan difundida y peligrosa, en el equívoco de criterios, que aquella del nacionalismo. En nombre de un

\footnotetext{
Luis Carlos Rodrigo fue quien obtuvo una resolución del Consejo Superior de Contribuciones para que las donaciones al I.A.C pudiesen ser deducidas por el doble de su valor de su renta gravable.

"A la presentación de Urteaga fue invitado el propio Sabogal quien había "descubierto" a este pintor cajamarquino en 1919 y analizó su pintura provinciana y costumbrista -candorosa y fuerte-como un arte social o un documento plástico y poético que no se extingue jamás en nuestro país (Cultura Peruana No. 87 , 1955 y "Exposición-Homenaje a la obra del pintor peruano Mario Urteaga organizada por el Instituto de Arte Contemporáneo" de José Sabogal Dieguez. Obras Literarias Completas. Lima, 1989, pgs. 261-266 ). También se escucharon los comentarios de Luis Miró Quesada y del pintor Fernando de Szyszlo, dos de los más destacados defensores del arte abstracto en el país (véase, Gustavo Buntinx "Las excelencias de la raza: inscripciones indigenistas de Mario Urteaga" en Mario Urteaga. Nuevas Miradas. Gustavo Buntinx y Luis Eduardo Wuffarden. Museo de Arte de Lima, Fundación Telefónica, 2003, pgs. 50-51). Para Szyszlo la pintura de Urteaga era naif en su sentido etimológico natif, natural o sin artificio- y estaba emparentada con el mejor arte popular y la creatividad pura pero aprovecha la coyuntura para citar a Picasso y señalar el talón de Aquiles de los pintores realistas-sociales que buscaban transformar el orden político con sus composiciones indigenistas: No es necesario pintar un hombre con un fusil, una manzana puede ser igualmente revolucionaria (Szyszlo, op.cit, p.85). Era en el orden plástico, y no en el político, donde se transformaba la visión interior. Posteriormente Szyszlo argumentaría que el verdadero arte colonial no era la originalísima pintura cuzqueña del virreinato peruano sino la pintura limeña del siglo XIX que copiaba y era del todo dependiente no a Delacroix ni de Courbet, sino de los pintores académicos franceses de segunda categoría y de Salón. También reconoce que si bien la pintura indigenista inaugurada con Sabogal constituyó la primera gran batalla por el arte moderno en el Perú, era lamentable que su calidad artística no estuviera a la altura de la función histórica que cumplió (Szyszlo, op. cit., 137-141). Para Sabogal, por su lado, el que el abstraccionismo no trabajara la forma, ni la respetara ni la sufriera lo convertía en un arte de decadencia, muy natural en pueblos que han recorrido enormes distancias y ciclos estéticos! Aqui [en el Perú], felizmente, estamos alboreando, saliendo del primitivo y nos falta mucho para ello ("José Sabogal, maestro pintor: un reportaje de César Francisco Macera" en Sabogal, op cit. p. 404). Sin embargo, Sabogal termina por reconocer -de hecho influido ya por la nueva corriente esteticista difundida por el I.A.C.- que los arcaicos artistas del Tiahuantinsuyo fueron maestros brillantes en sus composiciones religiosas "super-realistas" y "abstraccionistas", como ahora se dice (Sobre las representaciones artísticas abstractas en la iconografia indigena antigua y el realismo en la Imaginería en el arte hispano, en Obras literarias, op. cit, 1989, p. 165). En la última entrevista realizada a Sabogal en el diario El Comercio (el 21 de diciembre de 1956, p.21), sostiene que los mejores artistas que había conocido en su vida eran los de las culturas Nazca, Chimú y Paracas del Perú Antiguo y Pablo Picasso (agradezco la referencia a David Vargas Torreblanca).

Revista Amauta 6/2/1927.
} 
arte nacional se exaltan y defienden obras de la más baja calidad, basta que contengan una llama o un bote de totora. Con razón exclamaba Vallejo: me friegan los cóndores. En nombre de un arte nacional se niegan y atacan creaciones de innegable valor artístico, si ellas han sido dadas al margen de preocupaciones nacionales [...]. Nos preguntamos ¿Qué es más propio, más ilustrativo y más exacto: hablar del arte de un país o del arte en un país? [.. . L La negación de la universalidad, enmascarada detrás de la negacion de la particularidad, no puede transformarse en algo positivo, $y$ de aquí la notoria infecundidad de todos los nacionalismos ${ }^{12}$.

Por todo ello, el I.A.C realizó exposiciones retrospectivas de renombrados artistas internacionales como Adja Yunkers (1957), José Luís Cuevas (1958), Armando Morales (1959), Alejandro Obregón (1960), Maria Luisa Pacheco (1961), Lynn Chadwick (1962), Arcangelo Ianelli (1962), Henry Moore (1962), Jack Squier (1963), Alan Davie (1964), Joseph Albers (1964), Jacques Lipchitz (1965), Roberto Matta (1966), entre otros. En 1972 presentó en Lima la gran exhibición de arte surrealista del Museo de Arte Moderno de Nueva York. El I.A.C también exaltó a los artistas nacionales: a Fernando de Szyszlo (en 1955, 1956, 1957, 1959, 1960, 1961, 1962, 1965, 1968), Alberto Dávila (1955, 1961, 1963, 1965), Emilio Rodríguez Larraín (1955, 1964), Teofilo Castillo (1957), Alfonso Winternitz $(1957,1965)$ Macedonio de la Torre (1959), Reinaldo Luza (1959), Cristina Gálvez (1959, 1964), Tilsa Tscchiya (1959, 1968, 1970), Gerardo Chávez (1960), Sérvulo Gutiérrez (1961), Marina Núñez del Prado (1962, 1965), Joaquín Roca Rey (1962), Ricardo Grau (1962), Carlos Aitor Castillo (1963), Julia Codesido (1964) y Jesús Ruiz Durand (en 1968), entre otros. Sin embargo, en sus inicios el I.A.C organizó muestras sobre la Escultura lítica del Perú precolombino, sobre Las pinturas del Perú precolombino, el Arte Profano en la Escuela Cusqueña y patrocinó en 1957 una exhibición de acuarelas costumbristas y conferencias precursoras a cargo de Raúl Porras Barrenechea y de Jaime Bayly, sobre la obra del artista mulato Pancho o Francisco Fierro (1807-1879).

La misma presencia de José María Arguedas (1911-1969) y de Sebastián Salazar Bondy (1924-1965) en el I.A.C era sintomática. Arguedas era el antropólogo peruano más lúcido que a mediados de los años cincuenta buscaba un diálogo de apertura y acercamiento entre el campo y la capital por medio del apoyo a las artes populares tradicionales. En la zona de Huamanga, Arguedas tomó plena conciencia de que la cultura industrial moderna había producido en las clases sociales mestiza y señorial provinciana una grave crisis religiosa [...] que es el resultado de la transición violenta, de un proceso de autodespojo de creencias y no de la reflexión ${ }^{13}$. Por su parte, Sebastián Salazar Bondy -pese a haber presentado y elogiado una de las exhibiciones de Szyszlo- se

\footnotetext{
${ }^{12}$ Luis Miró Quesada. Arte en Debate. Facultad de Arquitectura. Universidad Nacional de Ingeniería, Lima, 1966, pgs. 139-157. Quizás por estos reparos, uno de los estatutos del I.A.C. advertía: el objeto de la asociación es dedicarse a toda clase de actividades culturales, sin restricción de ninguna clase y, especialmente, investigar, presentar, exhibir, divulgar, y estimular el arte en todos sus aspectos universales, y especialmente, las artes plásticas contemporaneas peruanas y americanas, mediante la realización de premios o estímulos, realización de cursos, organización de foros, congresos, organización de museos y en general, por cualquier otro medio cultural o de difusión adecuadas a sus finalidades.

José María Arguedas. El arte popular religioso y la cultura mestiza. Lima, 1958, p.151.
} 
convertiría en uno de los más duros detractores peruanos del arte abstracto que calificaba como un ejercicio cromático de limitada trascendencia por la pobreza imaginativa lamentable de quienes han convertido la creación artística en un inocuo deporte, en una gratuidad absoluta, en hacerla innecesaria. La humanidad integra interviene en la lucha [social], excepto los artistas: he aquí la traición ${ }^{14}$.

Sea como fuere, la revalorización del arte antiguo no era un caso aislado emprendido por el I.A.C. En un artículo de 1955 titulado Estilos en el Arte Peruano, Luis E. Valcárcel director del Museo Nacional de Historia- menciona que la exhibición de arte prehispánico organizada un año antes por el Museo de Arte Moderno de Nueva York y que viajó a San Francisco, Miniápolis y México, por primera vez en la historia había puesto en valor piezas arqueológicas que suscitaron una polémica entre los críticos internacionales de arte moderno. Con aguda visión histórica y esteticista, Valcárcel explicaba los alcances de esta nueva mirada al arte peruano:

En presencia de las esculturas Mochica y de las pinturas Nazca y Paracas, frente a los vasos de madera incas y a los adornos de oro chimus, se aviva la polémica y corren las voces que traen a cuenta abstraccionismo, superrealismo y suenen los nombres de Picasso, Klee, Braque [...]. El arte antiguo del Perú ha aparecido ante los ojos del mundo occidental en el preciso momento, cuando la sensibilidad de las élites de Nueva York, Londres, París o Roma, estaba preparada a entenderlo y valorizarlo. Antes, la gente estuvo a ciegas, de estas formas de arte; nada supo apreciar $|\ldots|^{15}$.

Este cambio de actitud fue posible gracias a los pintores y escultores revolucionarios de este siglo. Siendo espíritus selectos prepararon el camino cuando: comenzaron a cansarse del academismo y se fue formando el ambiente para aceptar como obras de arte las creaciones extraeuropeas, como las esculturas de madera de los negros de África o los tejidos cubistas tiahuanacoides del Perú. El arte popular ascendió a los salones y el Torito de Pucará puede hoy pasearse ufano por encima de un mueble Boule o por debajo de un Goya millonario ${ }^{16}$.

La referencia de Valcárcel al torito artesanal de Pucará bajo un Goya millonario aludía a la casa del propio Mujica Gallo quien en 1955, había adquirido de Bob Gésinus un lienzo de Goya titulado El indio americano Mariano Ceballos, puesto a la venta en Lima

\footnotetext{
Véase, Miró Quesada G, 1966, op.cit.pgs. 171-172. En su "Respuesta a Szyszlo" añade: Me gusta pensar que, en cierto modo, los americanos somos seres religiosos, es decir, primitivos y elementales y que esa religiosidad terrena y material constituye una cantera intocada de nuevas ideas, nuevas conquistas y nuevas luces que resultaría en un arte épico. Pero el arte abstracto era la forma más refinada y sutil del suicidio (La Prensa. 28 de Junio de 1954). Szyszlo responde indirectamente a estas críticas dándole nombres con contenidos históricos peruanistas a sus composiciones abstractas inspiradas en el arte prehispánico: Cajamarca (1959), Illa (1960), Paraca (1961) Yawar Fiesta (1963), Apu Inka Atawallpaman (1963), La ejecución de Tupac Amaru (1975), Incarri (1968) etc. De hecho, en su Poesía quechua y pintura abstracta (1964) Emilio Adolfo Westphalen argumenta a partir de esto que la pintura de Szyszlo era un arte "comprometido" que propugnaba ideales culturales afines a los problemas sociales y éticos de su época (Para la despolitización de Szyszlo durante la dictadura militar (1968-1975), véase, Alfonso Castrillón Vizcarra "Szyszlo frente a la critica" en Hueso Humero. No. 5/6. 4 de Diciembre de 1978, pgs. 77-87).

Luis E. Valcárcel "Estilos en el arte peruano antiguo” en Cultura Peruana. XV Aniversario. No. 90. 1955.

Ibíd. . En la revista Fanal (Vol X, No. 42, 1955, p.4) Valcárcel también destacaba la enorme trascendencia |... que el Museo de Arte Moderno de Nueva York, esa catedral de la cultura artística de nuestro tiempo, en que se guardan sus obras maestras (los Picasso, los Utrillo, los Braque, los Juan Miró, los Klee...), abrió, por primera vez, sus puertas a las obras de arte del Perú antiguo, en esplendente exposición que deslumbró a la alta sociedad neoyorkina que dicta sus fallos con carácter universal.
} 


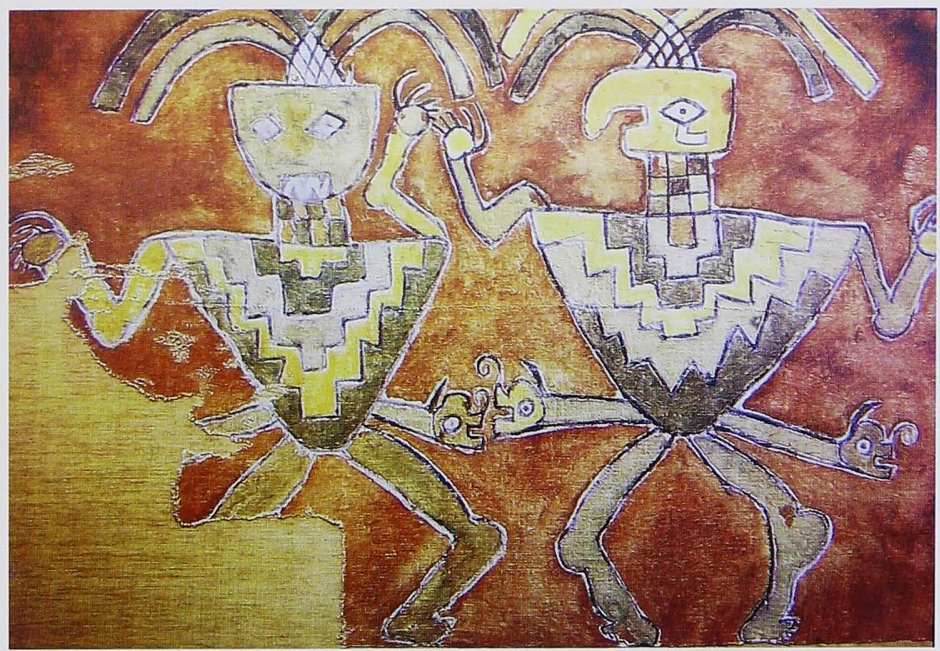

(fig.3) Tela pintada Chancay con personajes "picassianos"

por la Galería Wildenstein de Nueva York. A la belleza de la obra pronto se sumó su significado peruanista. En un artículo del 9 de noviembre de 1958, Aurelio Miro Quesada dio a la luz una escritura pública fechada en 1779 proveniente del Archivo de los Condes de la Vega del Ren, que esclarecería la misteriosa identidad del torero Mariano Ceballos cuatro veces retratado por Goya. Conocido en España por su temeraria proeza de matar a un toro desde otro toro ensillado y con grietes para los pies, Mariano Ceballos no era de raza indígena sino negra. Era un esclavo criollo, oriundo de Lima, al cual se le había condicionado su libertad para que no toreara ${ }^{17}$.

Valcárcel -compartiendo la perspectiva continentalista del presidente del I.A.C.- no vacila en identificar los diversos estilos del arte prehispánico con las corrientes del arte moderno. Los retratos Mochica eran análogos a las representaciones antropomórficas realistas. Los aríbalos Inca eran un arte no figurativo, sino simbólico. Las telas pintadas Chancay estaban repletas de representaciones superrealistas y respecto a su estilo, podría verse un cierto picassianismo, algo que pudieran encontrar simpático los surrealistas. Se trata de una intencional deformación: el sentido de este: son y no son hombres los aqui pintados, recuerdan la figura humana, pero son seres míticos ${ }^{18}$ (fig.3).

\footnotetext{
7 Se deduce de la Escritura Pública publicada por Aurelio Miró Quesada que en más de una ocasión, su afición al toreo habría puesto en peligro la vida de Ceballos motivo por el cual cuando el Conde de Santa Ana de las Torres le otorgó la libertad a este criado, la condicionó a que no toreara de pie, ni a caballo o parado sobre cualquier paraje o puesto voluntariamente frente a un toro, promesa que Ceballos aparentemente cumpliría aunque burlando el objetivo de su antiguo patrón, con un nuevo e ingenioso arte de rejoneo (Véase, Aurelio Miró Quesada S. 20 temas peruanistas, Lima, 1966, pgs. 345-355).

${ }^{18}$ Valcárcel, Cultura Peruana. Op. cit. 1955.
} 


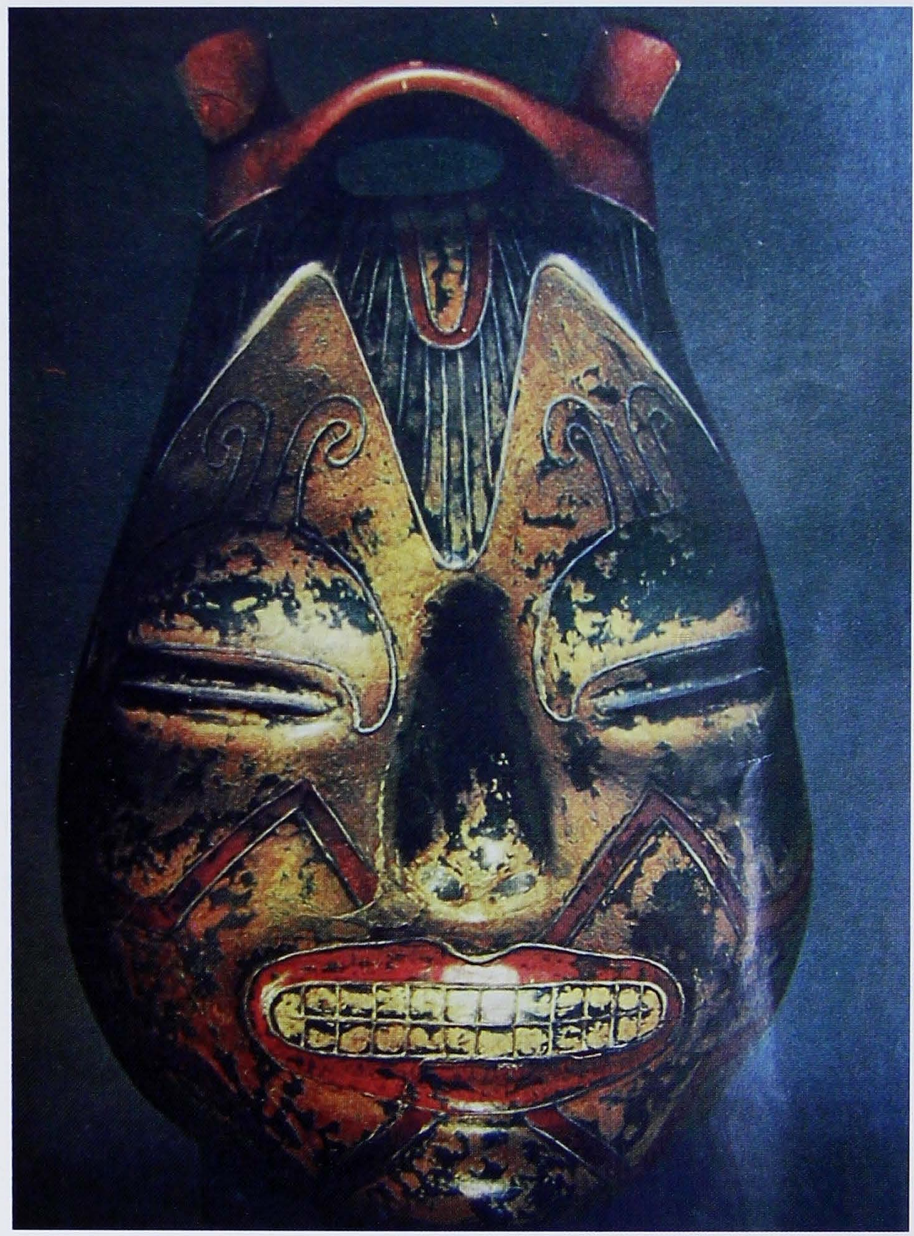

(fig.4) Huaco "Paracas" de "fabricación Sérvulo Gutiérrez", 1932 
Un curioso incidente relacionado con la exhibición del Museo de Arte Moderno de Nueva York profundizó esta polémica esteticista: uno de los ceramios estrella seleccionado por dicho museo y publicado por la revista Life ${ }^{19}$. como máximo símbolo de la estética del hombre Paracas cavernas de hace dos mil años de antigüedad era, en realidad, una obra fabricada en 1932 por un artista plástico del Perú contemporáneo: Sérvulo Gutiérrez ${ }^{20}$ (fig.4). La noticia hizo titulares de primera página en el diario limeño de La Prensa y cuando se le preguntó al Dr. Valcárcel por su docta opinión al respecto, comentó que esto les sucedía a los organizadores extranjeros por no haber consultado con los arqueólogos peruanos. Hacia años que aquella pieza "arqueológica" había sido puesta en "cuarentena" por los especialistas. Incluso: Mientras sonreía el Dr. Valcárcel afirmó que si bien la cabeza trofeo de fabricación Gutiérrez no era valiosa desde el punto de vista arqueológico, lo era por su gran calidad, desde el punto de vista artístico. Sérvulo Gutiérrez, a su vez, al ser informado sobre la opinión de los arqueólogos, replicó: Yo no hice los huacos por falsificarlos. ¿Qué culpa tengo yo, que trabaje tan bien como los antiguos Paracas? Luego añadió: muy pocos sabian que yo también era huaquero ${ }^{21}$. El hecho de que un artista plástico contemporáneo buscara inspiración en una cultura primitiva y fuera condicionado por su colorido y estética al punto de hacer originales que pasaban por obras maestras antiguas suscitaba otros dilemas. Jorge Donayre lo sintetiza en La Prensa: esto significaba que así como en el Antiguo Perú existieron alfareros cuyas obras han asombrado al mundo, es posible que aún en el Moderno [...] de 1930 a 1954 existieran alfareros capaces de hacer equivocarse a los mejores arqueólogos del mundo ${ }^{22}$.

En el mismo año, Luis Miró Quesada, retoma esta polémica esteticista mencionada por Valcárcel en el comentario introductorio que escribe para el catálogo de la exposición sobre telas pintadas prehispánicas que, con el apoyo del escultor Joaquín Roca Rey, organiza para el I.A.C. Asocia la espontaneidad creativa de la pintura Chancay con el arte moderno y le advierte al público visitante que el sentido e intención de aquella muestra era estrictamente artística y no arqueológica. Aunque no lo menciona por su nombre, Miró Quesada asume los prejuicios decimonónicos y evolucionistas de la antropología psicologista de Lévy-Bruhl para quien la mentalidad primitiva -a diferencia de la del hombre racional civilizado- era una ideación colectiva que correspondía a una etapa infantil y pre-lógica de la humanidad. Pese a esto, rescata el sentido poético, supra-real, algunos dirían metafísico, de la abstracción pictórica

\footnotetext{
"En Life en español del 26 de abril de 1954 aparece una nota titulada Tesoro de Arte Andino con las fotografias de las piezas legadas por viejas civilizaciones que se estaban exhibiendo en los Museos Norteamericanos. De las 400 piezas exhibidas se mostraba este huaco excepcional que Sérvulo al verlo juro y rejuró según La Prensa- que era, junto con otros tres ejemplares en otros Museos extranjeros obra suya, realizada durante sus años mozos cuando se dedicaba a la alfarería y a la restauración de ceramios antiguos.

*Véase Elida Román y Luis Eduardo Wuffarden. Sérvulo Gutiérrez 19141961. Patronato de Telefónica y Museo de Arte de Lima, 1998, p. 368.

${ }^{21}$ Vease, Jorge Donayre B. "Huaco al que atribuyen unos 2000 años habría sido hecho en Lima en 1932 " en La Prensa, 11 de mayo de 1954. Le agradezco la gentileza a L. E. Wuffarden por esta referencia.

¿ Jorge Donayre B "Imitación de Sérvulo Confundió a Museo en E.U. Prueban que el Huaco Paracas es Falso" en La Prensa, 16 de mayo de 1954.p. 2.
} 


\section{primitiva $^{23}$ :}

Para la percepción cabal de un arte de hoy es necesario alcanzar el estado exacto del hecho artístico cualquiera que sea su expresión, es necesario ampliar horizonte y profundizar raíces [...]. Aunque cronológicamente [las telas pintadas] parecen corresponder a una época tardía [a la cultura Chancay], espiritualmente constituyen un arte de inicio, formalmente [... / son representativas de un arte primitivo y por ello quizás, cercano a la comprensión del arte contemporáneo-. Las suyas son formas elementales y de inicio, no elaboradas y de culminación [...]. Como en toda manifestación pictórica primitiva, o cualquier dibujo infantil, aqui ła figuración con elementos simples y trazos torpes se resuelve en eficaces convencionalismos expresivos que devienen formas significativas. Ello, quizás, en aquel espontáneo reducir a lo esencial y en ese innato vigor de expresión propio de toda sensibilidad humana de un estadio pre-lógico y pre-racional|...]. Puede, quizás, apuntarse como característico de estas telas, un sentido de composición liberado de cánones y reglas [...] Por momentos, mirando estas telas, viene a nuestro recuerdo los universos de Miró o de Klee; un universo pre-racional que es como decir supra-real $|. .$.$| y poético |\ldots|^{24}$.

La cita es valiosa pues sintetiza el discurso cosmopolita del I.A.C. frente al arte del Perú Antiguo. A Mujica Gallo, empero, no le bastaba conocer teóricamente las similitudes formales entre lo prehispánico y lo moderno. Se propuso abordar al propio Picasso para someter los postulados estéticos de su mirada comparativa al juicio del pintor.

Mujica Gallo se entrevista con Picasso en dos oportunidades: en 1960, en Arles y en 1968, en Cannes. La primera vez fue con motivo de una corrida de toros: un mano a

${ }^{23}$ Tal como lo señaló tempranamente Paul Radin en su Primitive Man as Philospher (1956.), no existía una diferencia ontológica real entre la capacidad lógica y simbólica del hombre "civilizado" y la del así llamado "primitivo". La mitología de las tribus africanas, australianas o amazónicas operaba con el mismo vocabulario simbólico universal que el empleado en la Antigüedad Clásica, en el Oriente, la Edad Media Europea y el Renacimiento Italiano, por no mencionar a las nuevas mitologías cientifistas, seculares y bélicas con carácter globalizador vigentes en nuestras nuevas selvas urbanas (Sobre los cambiantes paradigmas culturales en Occidente véase: Arthur O. Lovejoy The Great Chain of Being. A Study of the History of an Idea. Harvard University Press, 1963; Mircea Eliade, Patterns in Comparative Religion., New York, 1963; Thomas S. Kuhn, The Structure of Scientific Revolutions, The University of Chicago Press, 1962. Huston Smith, Beyond the Post Modern Mind. New York, 1982; Fernando Fuenzalida. Tierra Baldia. La crisis del consenso secular y el milenarismo en la sociedad postmoderna. Colección Axis Mundi. Lima, 1995).

La diferencia entre la mentalidad simbólica primitiva y la mentalidad secular moderna es filosófica y cosmológica. Para los primitivos el universo tenía distintos niveles de realidad cósmica y todas sus artes o manufacturas utilitarias eran funcionales y rituales a la vez. Sus diseños abstractos o realistas -lejos de ser meramente decorativos, ornamentales, naturalistas o, in-significantes, en un sentido moderno- tenían un contenido algebraico: una densidad metafísica y abstracta que articulaba su visión tradicional del cosmos. Por otro lado, para la mentalidad profana, enmarcada en las ciencias empíricas y el positivismo racionalista, el mundo o la existencia corpórea era reducible aritméticamente a sus componentes materiales y la experiencia estética del hombre no iba mas allá del ámbito subjetivo y pasional de su psique y de los sentidos físicos, lo cual explicaba la falta de propósito en el arte moderno. A partir de esta distinción, la célebre sentencia de John Lodge: De la Edad de piedra a nuestros dias quelle dègringolade (véase, A.K. Coomarswamy "Primitive Mentality" en Coomaraswamy. Selected Papers. Traditional Art and Symbolism. Edited by Roger Lipsey. Bollingen Series, Princeton University Press, 1977, pgs. 286-307 ; del mismo autor, La filosofia cristiana y oriental del arte. Taurus, Madrid, 1980 y Seyyed Hossein Nasr, Knowledge and the Sacred. The Gifford Lectures, 1981, Edinburgh University Press, 1981).

${ }^{24}$ Luis Miró Quesada, "Pinturas del Peru Precolombino". 1 Cuadernos del Instituto de Arte Contemporáneo al cuidado de Javier Sologuren. Lima, (s/f). Para una "lectura" de la estética prehispánica con categorías contemporáneas véase, Juan Manuel Ugarte Eléspuru. Las telas pintadas precolombinas de la costa peruana. Banco Central de Reserva del Perú, Lima, 1995. 
mano entre Luis Miguel Dominguín amigo íntimo del pintor y de Mujica Gallo- y Ordoñez. Como enviado especial del diario Pueblo en Arles, Antonio D. Olano publica en Madrid el 13 de julio de aquel año las entrevistas que sostuvo con los personajes allí reunidos bajo un titulo largo, noticioso y llamativo: Picasso, Bernard Buffet, Annabelle, Yul Brinner, Mujica y Jean Cocteau (en la órbita del taurinismo) hablan para Pueblo. Picasso quiere ver a un ceramista en Cuenca. "Fue Goya figura del toreo?"25. El paralelismo Goya-Pedro Romero y Picasso-Luis Miguel discutido por el poeta peruano y el pintor español. El ceramista español inventor del toro de Cuenca que Picasso quería conocer era Pedro Mercedes y la pregunta sobre Goya como figura del

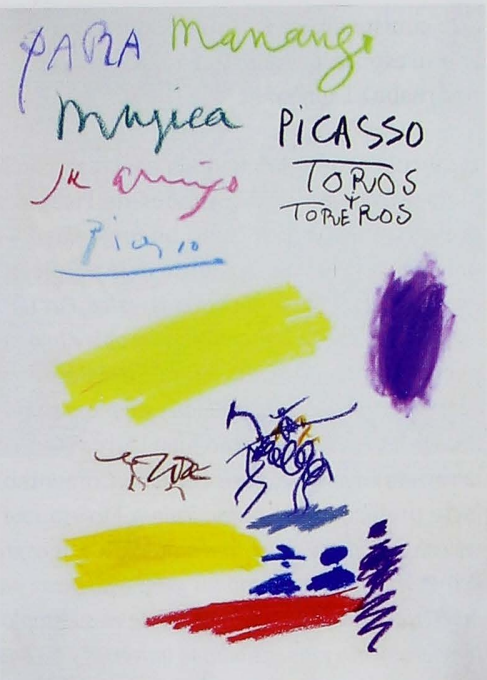

(fig.5) Dibujo original de Picasso autografiado para Manuel Mujica Gallo. toreo era el título del libro que Mujica tenía escrito en aquel entonces y que en discusiones pictóricas comparte y discute con Picasso y Jean Cocteau. Este último era profesor de música del pintor y medio siglo atrás, en Roma, Picasso había trabajado para él decorando los telones para sus ballets ${ }^{26}$. (fig.5). Aquella tarde en el ruedo, Luis Miguel Dominguín le brindó el toro a Picasso y una vez terminada la corrida, el artista se fue a conversar con Mujica a la terraza de un café en Arles. Sus diálogos continuaron aquella noche en casa de David Cooper, el más grande coleccionista de

\footnotetext{
${ }^{25}$ ¿Fue Goya figura del Toreo? es el titulo del libro que Mujica Gallo publica en Lima en 1960. La amistad entre el pintor y el escritor peruano lo ratifica D. Olano en otra nota periodística fechada el 22 de Julio de 1960 y titulada "A la busca de los Picasso Coruñeses" donde informa que a solicitud de Picasso: Mujica Gallo, amigo íntimo del pintor malagueño, trae el encargo de remitirle reproducciones fotográficas de cuantos posibles cuadros suyos encuentre en La Coruña, lo que comunico para la información de aquellos que se crean en posesión de tales tablillas-que es lo que fundamentalmente dejo aqui el niño Pablo Ruiz.

${ }^{26}$ Según Mujica Gallo la fascinación de Goya y de Picasso por lo taurino explicaba la afinidad e identificación que cada uno tenía con la máxima figura del toreo de su tiempo: Pedro Romero para Goya y Luis Miguel Dominguín para Picasso. El periodista Antonio D. Olano recoge los argumentos y paralelismos entre Goya y Picasso que Mujica le plantea al pintor en su presencia: Creo que los dos, por su amor a lo taurino, tienen una gran a finidad. Es total la identificación de Goya y Pedro Romero. Como lo es ahora la suya con Luis Miguel. La historia vuelve a repetirse. Todo lo que hizo Pedro Romero fue bajo el dominio intelectual de Goya [...]. Romero toma la alternativa cuando Goya llega a Madrid. Coinciden en la misma fecha. Goya era un gran pedante del toreo. Spengler dice que sus cuadros son confesiones taurinas. Y tiene razón. La emoción que producen los cuadros de Goya no es emoción pictórica, se parece mas a la emoción taurina. Goya se autorretrata vestido de torero [.... Picasso siente no tener argumentación para hacer mayores las coincidencias, las analogías [...] que busca Mujica Gallo entre Goya [... y Picasso [...]. Dice tímidamente: Y antes que un tal poeta, mi deseo primero hubiera sido ser un buen banderillero" (A. D. Olano. Picasso Intimo. 1971. Noventa años (Editorial Dador, Madrid, 1971, p. 81. La referencia me ha sido gentilmente proporcionada por Luis Carlos Rodrigo).

Una década después Mujica Gallo cambiaria de parecer. Se enfrentaría al mito Picasso para culpar a sus mini-toros, coreografiados rítmicamente al estilo de ballets, pero sin casta ni fiereza como una de las causas de la decadencia de la fiesta brava (véase, Manuel Mujica Gallo, La minitauromaquia de Picasso o el ocaso de los toros. Madrid, 1971).
} 
arte cubista en Francia, que le daba una cena a Picasso y a la que Mujica fue invitado con su esposa a pedido y en representación de Dominguín, quien no pudo asistir pues retornaba a España.

El vínculo profundo que unía a Picasso con Mujica era la amistad de ambos con Luis Miguel Dominguín y el interés de Picasso por el Perú. Dominguín, además, había presentado a Mujica como un arqueólogo y escritor peruano. En aquella ocasión el pintor le reveló un dato que lo dejó perplejo: Tengo un antepasado del siglo XVII que hizo mucho por Perú y que allí dejó sus restos. Fue un esforzado guerrero y sacerdote, bisabuelo de mi padre. Se le conoce como el venerable Almoguera ${ }^{27}$. Su aprecio por el arte prehispánico peruano le venía de muy atrás. En la década de los años treinta, Picasso había visto en Paris cajas enteras de huacos y de piezas prehispánicas en metal llevadas a Europa del Perú por el poeta bilbaino Juan Larrea (1895-1980), quien junto con Cesar Vallejo creó la revista Favorables París Poema ${ }^{28}$. Comentaba Mujica Gallo: El lenguaje plástico de éste [arte prehispánico] comunícale a Picasso una extraña emoción artística que él enfoca y retiene en toda su espontánea simetría. Los cántaros, los felinos, los pumas, las lechuzas, los keros, las llamas, las manos y las máscaras parecen sonreír a los ojos y a las manos del maestro. $Y$ sin duda háblanle a éste en su propio lenguaje revolucionario, persuasivo para el temperamento y la sensibilidad universal y atrevida de Picasso.

Pablo Ruiz le advierte que no tenía que ir muy lejos para demostrarle la influencia que esta cultura ejercía en su vida. El medallón de oro hecho por él que lucia la dama que lo acompañaba en Arles copiaba una antigua deidad peruana aunque jugueteando [Picasso] subrayó que para evitar confusiones entre los arqueólogos, al reverso de la joya había estampado sus señas personales. Tanto él como su esposa Jacqueline Roque vestían con frecuencia el poncho peruano (figs. 6, 7). Desde 1947 labra figuras en cerámica del cóndor andino y en 1954 pinta escenas de circo sobre ceramios esmaltados en blanco que tienen la forma de huacos Mochica de asa estribo. Según Juan Larrea, el dibujo de un venado atravesado por una lanza que se encuentra representado sobre uno de estos ceramios Mochica estaba ejecutado con un sentimiento plástico parecido al del caballo del Guernica ${ }^{29}$ (figs. 8,9,10).

Después de su segundo encuentro con Picasso en Cannes, en 1966 (figs.11,12),

Véase, Manuel Mujica Gallo "Un ilustre antepasado de Picasso: el venerable arzobispo de Lima don Juan de Almoguera" en La vanguardia española. Domingo 28 de Mayo de 1967, p. 57. Almoguera -le corrigió Mújica Gallo- no podría haber sido bisabuelo (directo ascendiente) de don José Ruiz, padre del genial pintor malagueño, sino tío bisabuelo de este y, en consecuencia, tío tatarabuelo de Picasso. Ante el artista quedó asi constancia exacta de su relación consanguinea con el santo prelado. Pese a ello, el 16 de Enero de 1961 Picasso le envía a Lima de obsequio el libro ortografiado de Jaime Sabartés Picasso. Documents Iconographiques, editado por Pierre Cailler y publicado en Ginebra en 1954 donde aparece un retrato dieciochesco de Almoguera y se estudia su parentela con Picasso. Sobre el obispo moralizador Fray Juan de Almoguera (1605-1676) -arzobispo de Arequipa y Lima- y autor de una Instrucción de curas prohibida por la Inquisición española, véase, Ventura Travada, "El Suelo de Arequipa Convertido en Cielo" (1752) en Documentos Literarios del Perú. Tomo X. Manuel de Odriozola. Lima, 1877, Págs.134-150).

${ }^{28}$ En 1938, tras la muerte de César Vallejo, Larrea incluso le solicitó a Picasso que ayudara a recaudar fondos para el entierro del poeta peruano. Le leyó los poemas La rueda del hambriento y España, aparta de mi este cáliz y el pintor, valiéndose de una fotografía de Vallejo, a quien nunca conoció, dibujó tres retratos sobre stencil u hoja de cera utilizada en los aparatos multicopistas (comunicación personal de Fernando de Szyszlo, véase también Juan Larrea. Al amor de Vallejo. Pre-Textos, Valencia, 1980, pgs.101102).

Juan Larrea. Pablo Picasso. Guernica. Cuadernos para el Dialogo. Madrid, 1977, p.151. 


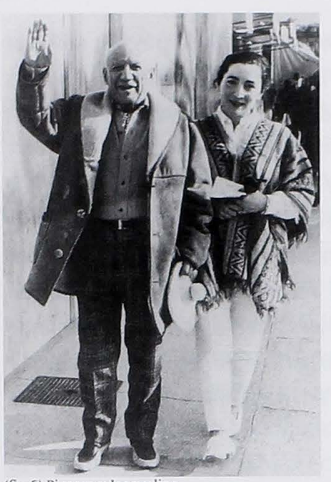

(fig.6) Picasso y Jacqueline

usando el poncho peruano.

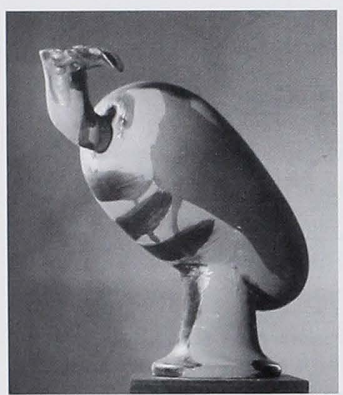

(fig.8) Cóndor picassiano. 1947.

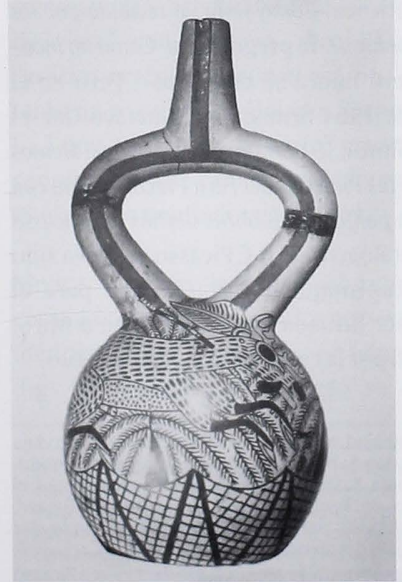

(fig.10) Ceramio Moche con la imagen del venado herido.

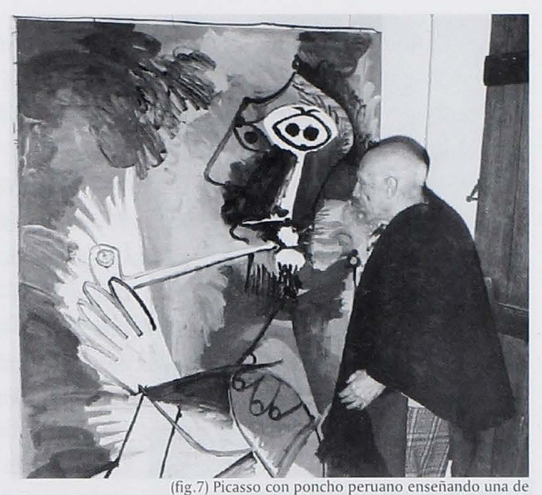

sus ultimas creaciones en abril de 1969.

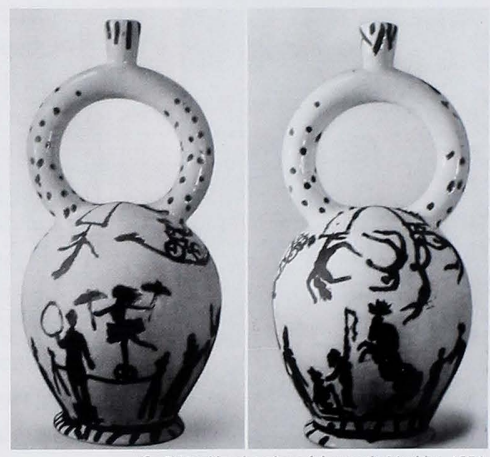

(fig.9) Versión picassiana del ceramio Mochica. 1954
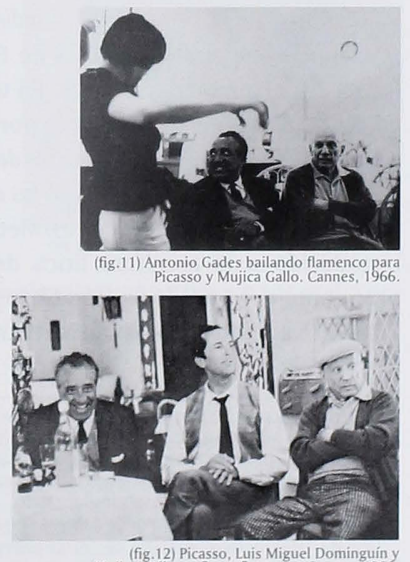

Mujica Gallo en fiesta flamenca. Cannes, 1966. 
Mujica Gallo decide hacer pública su amistad con el pintor y desde la página cultural de Die Presse (4/1/1968) en Viena y del $A B C$ (16/6/1968) de Madrid reta a los especialistas para que estudiaran este auto-confesado derrotero visual del opus picasiano $^{30}$. Mujica reconoce:

Tan sólo Picasso o algunos estudiosos del proceso de su arte podrían precisar en qué medida ese arte prehispánico influye en su obra excepcional. Me limito yo en estas líneas a repetir lo que Picasso me aseguró hace algunos años reiterándome ahora, en presencia de mi hijo. Lo dijo con euforia juvenil reconstruyendo en su movida conversación ese momento vital en que su mirada descubre dentro de ese mundo arqueológico las altas calidades de este: creaciones artísticas subjetivas, armónicas y libres moldeadas con refinado buen gusto por manos de razas milenarias del Perú hoy melancólicas y mudas.

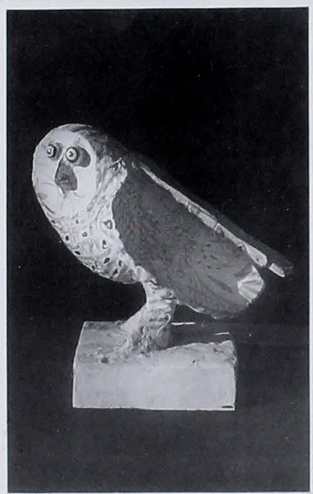

(fig.13) Lechuza picassiana inspirada en ceramio prehispánico.

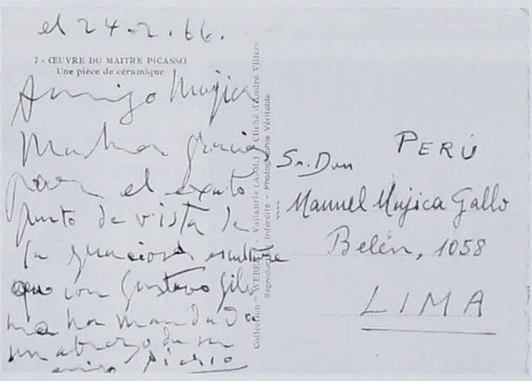

(fig. 14) Reverso de postal de Picasso enviada a Mujica.

En Arles, Picasso ya le había mencionado su enorme interés por conocer la ciudad del Cusco y de llegar a las aguas del Titicaca. Como sería yo recibido por los indios al pie de ese lago? -le preguntaba- Como un inca-

en litera- le respondió. La visita de Picasso al Perú nunca se cristalizó ${ }^{31}$. Pero en el ínterin, intercambiaron misivas. En una postal de 1964 firmada por Gustavo Gili -el editor de Picasso en Barcelona- y por el propio pintor, le comunican a Mujica: Hemos hoy admirado los bonitos documentos del I.A.C sobre las Pinturas del Perú Precolombino con que Uds. nos obsequiaron junto con las últimas y tan polifacéticas obras hechas por Picasso siempre sorprendentes y magnificas. Mediante un catálogo del I.A.C Picasso ya había sido introducido a la escultura lítica de Chavín, Cupisnique y Pucará. Pero para el presidente del I.A.C la pintura Chancay podría ser firmada por él, por Klee o Miró. Picasso lo admite y expresa su particular atracción por la cerámica del Perú antiguo.

\footnotetext{
${ }^{30}$ En 1966, poco antes de presentar sus credenciales como Embajador del Perú en Viena, Mujica Gallo viaja con su hijo Manuel a Cannes y asiste a una fiesta flamenca donde bailan Antonio Gades y Josefa Cotillo, "La Polaca" para Picasso, Luis Miguel Dominguin y el poeta Rafael Alberti. Picasso le reitera aquí el impacto mágico sobre su obra que ejercía el arte prehispánico del Perú, pero solo del Perú agregaba. (Véase. Manuel Mujica Gallo "Picasso Indianizado" en el $A B C$ de Madrid del 16 de Junio de 1968). En lo que sigue, las citas a Mujica provienen de las versiones manuscritas del mencionado artículo del ABC.

Uno de los directivos del I.A.C se opuso enérgicamente a la propuesta de Mujica Gallo de invitar a Picasso al Perú por tratarse de un artista afiliado al Partido Comunista francés.
} 
Dentro de este dialogo creativo y creador, Picasso le envía a Mujica otra postal que reproduce uno de sus ceramios (figs.13,14). Está fechada el 24 del febrero de 1966 y constituye la prueba definitiva e irrefutable de que empleaba modelos prehispánicos para sus composiciones. Amigo Mujica -le advierte el maestro- muchas gracias por el exacto punto de vista de la graciosa escultura que con Gustavo Gili me ha mandado. Un abrazo de su amigo, Picasso. La graciosa escultura era un ceramio perteneciente a la cultura Mochica que Mujica le había enviado al artista y que éste había recreado en su estilo propio:

Frente a una estatuilla de cerámica procedente de la cultura Mochica [...] no contiene Picasso su júbilo para decirme por escrito en el reverso de una postal que reproduce en fotografía a una lechuza modelada por sus manos, como ante un hallazgo que lo consagra a él, establece y subraya Picasso la identidad de la concepción escultórica de ese artista peruano sencillo y anónimo, envejecido en siglos de edad prehispánica, con el arte sutil siempre genial del vanguardismo suyo. Con humilde naturalidad escribe Picasso [...] dos líneas precipitadas pero significativas, acentuándome "el exacto punto de vista" con el suyo -dice Picasso- de la "graciosa escultura" con el espíritu creador por tanto de su propio modelado. Reconoce Picasso [...] que el "punto de vista" artístico de esos centenarios $[\ldots]$ ceramistas indígenas preincas es el mismo punto de vista que el de él.

Mujica también le había obsequiado otros

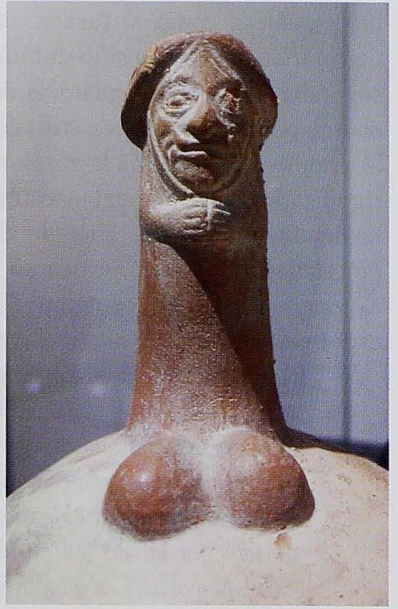

(fig.15) Falo con rostro humano de la cultura Moche.

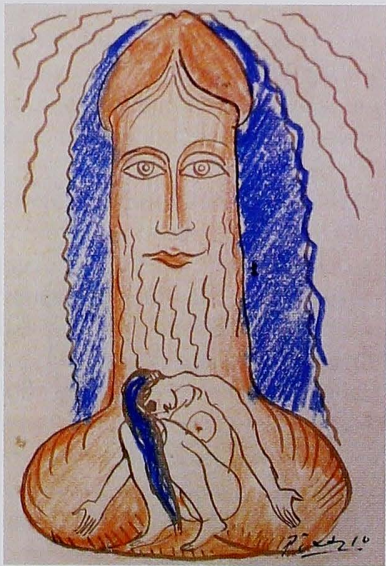

(fig.16) Falo con rostro humano de Picasso. 1903 ceramios de temática erótica que entusiasmaron al malagueño y cuya iconografía era idéntica a sus composiciones tempranas y que copiaría con pequeñas variantes ${ }^{32}$. (figs.15, 16). Picasso expresó su convicción de que si él firmaba estas obras

Recordemos que en la década de los años cincuenta y sesenta el malagueño reanudó, con diversos estilos y técnicas, su interés precoz por el erotismo. Retomó a Delacroix, a Degas, incluso a Rembrant, para representar al amante orgiástico, al beso, al abrazo, al acoplamiento. Utilizando el imaginario mitológico griego, enriqueció la iconografía de los raptos de los dioses con jovencitas en brazos de centauros y minotauros y graficó las cópulas promiscuas del pintor con su modelo (Vease, Brigitte Baer, Jean Clair, Dominique Dupuis-Labbé, Malén Gual, Maria Teresa Ocaña, Robert Rosenblum... [et. al] Picasso erótico. Catalogo. Institut de Cultura de l'Ajuntament de Barcelona. Museo Picasso, 2001). 
prehispánicas como si fuesen creaciones suyas, recién los críticos de arte se percatarían de que la visión sintética del arte primitivo era un rasgo que antecedía y superaba todas las vanguardias del arte moderno ${ }^{33}$. Es más, toda noción de arte contemporáneo entraba en crisis cuando el artista moderno se miraba en el espejo de lo primitivo y descubría la absoluta vigencia de sus postulados estéticos. Con esta significativa confesión del maestro, Mujica Gallo presiente que el arte prehispánico finalmente había sido liberado de su olvido y con una retórica incaísta, con pinceladas surrealistas, evoca un Tawantinsuyo utópico redimido por el máximo exponente del arte contemporáneo. Concluye su artículo Picasso indianizado, exclamando:

Picasso ha redimido el lenguaje culto de este arte autóctono. Las vicuñas desde arriba tan espirituales, cerca del cielo, allá en los Andes, se inclinan hoy como solo lo hacen las princesas. Ellas ahora con ese andar aristocrático y ese mirar esotérico se inclinan ante la majestad revolucionaria del espíritu de un artista generoso y contemporáneo, de un espíritu inagotable, libre e indianizado. Una multitud fantástica de huacos movidos por ñustas felices bailan rítmicamente después de siglos de postración y entonan su música en silbidos tristes pero victoriosos ${ }^{34}$.

\footnotetext{
33 Comunicación personal de Manuel Mujica Pinilla.

${ }^{34}$ Mujica Gallo. Op.cit. 1968.
} 